\title{
Structural Analysis of Saponins from Medicinal Herbs Using Electrospray Ionization Tandem Mass Spectrometry
}

\author{
Shuying Liu, Meng Cui,* Zhiqiang Liu, and Fengrui Song \\ Laboratory of Mass Spectrometry, Changchun Institute of Applied Chemistry, Chinese Academy of Sciences \\ Changchun, China
}

Wenjun Mo

Barnett Institute of Chemical and Biological Analysis, Northeastern University, Boston, Massachusetts, USA

The underivatized saponins from Tribulus terrestris and Panax ginseng have been investigated by electrospray ionization multi-stage tandem mass spectrometry $\left(\mathrm{ESI}^{-M S^{\mathrm{n}}}\right)$. In ESI-MS spectra, a predominant $[\mathrm{M}+\mathrm{Na}]^{+}$ion in positive mode and $[\mathrm{M}-\mathrm{H}]^{-}$ion in negative mode were observed for molecular mass information. Multi-stage tandem mass spectrometry of the molecular ions was used for detailed structural analysis. Fragment ions from glycoside cleavage can provide information on the mass of aglycone and the primary sequence and branching of oligosaccharide chains in terms of classes of monosaccharides. Fragment ions from cross-ring cleavages of sugar residues can give some information about the linkages between sugar residues. It was found that different alkali metal-cationized adducts with saponins have different degrees of fragmentation, which may originate from the different affinity of a saponin with each alkali metal in the gas phase. ESI-MS ${ }^{\text {n }}$ has been proven to be an effective tool for rapid determination of native saponins in extract mixtures, thus avoiding tedious derivatization and separation steps. (J Am Soc Mass Spectrom 2004, 15, 133-141) ( 2004 American Society for Mass Spectrometry

S aponin is an important class of natural products that can be found primarily in roots, petals and foliage of many plants, as well as in some marine animals. Most saponins possess a variety of bioactivities (e.g., cardiac, antifungal, hemolytic activities and abilities to affect metabolism and biosynthesis); they are among the major effective components in nutriceutical products and Chinese folk medicine [1-4]. A saponin molecule consists of an aglycone (or sapogenin) and one or two sugar moieties. According to the structures of the aglycones, saponins can be classified into two types: triterpenoidic and steroidal. The most common sugar residues are hexoses (glucose, galactose), 6-deoxyhexoses (furanose, quinovose, rhamnose), pentoses (arabinose, xylose), and uronic acids (glucuronic acid, galocturonic acid). The sugar moiety is linked to the aglycone through an ether or ester glycosidic linkage at one or two glycosylation sites. Because of their structural complexity and low abundance in some herbs, it is difficult

Published online December 9, 2003

Address reprint requests to Dr. S. Liu, Laboratory of Mass Spectrometry, Changchun Institute of Applied Chemistry, Chinese Academy of Sciences, Changchun 130022, China. E-mail: mslab@nc.ciac.jl.cn

*Current address: National Research Council of Canada. to structurally analyze the saponins. The general procedure, which involves extraction, isolation of the individual components followed by chemical manipulations and spectroscopic analysis, is tedious, time consuming, and insensitive $[5,6]$.

Mass spectrometry (MS) has played an important role in the structural analysis of saponins. In early studies, derivatization was required for saponin analysis using electron impact (EI) MS [7-9]. The development of desorption chemical ionization mass spectrometry (DCI-MS) allowed analysis of saponins without derivatization, but only for saponins with ether glycosidic linkages [10, 11]. Later, field desorption (FD) and fast atom bombardment (FAB) were also employed to analyze native saponins [12-18], providing information about molecular mass and sugar sequence by cleavage of glycosidic bonds. However, it is difficult to obtain high quality and reproducible FD mass spectra because of the instability of ion currents dependent on the temperature of the emitter $[13,14]$. The sensitivity of $\mathrm{FAB}$ is also not satisfactory because of the chemical noise from the matrix background [15-17]. More recently, electrospray ionization (ESI) has become one of the most effective analytical tools for the structural characterization of a variety of polar and thermally 
labile molecules, e.g., polypeptides, carbohydrates and natural glycosides [19-22]. Recent studies have reported the use of ESI-MS for determination of saponins with higher sensitivity and better reproducibility than the other types of ionization [23-28]. Moreover multistage mass spectrometry has great advantages for characterization of compounds by providing structural information [24, 25, 27-31].

In this paper, we apply the ESI-MS ${ }^{n}$ to systematically investigate structural characterization of underivatized saponins from different origins in the positive and negative ion modes, The fragmentation patterns of different alkali metal adducts with saponins are compared for structure analysis and rationalized from an internal energy point of view.

\section{Experimental}

\section{Materials}

The crude powder of Tribulus terrestris, Panax ginseng, and pure ginsenoside $\mathrm{Rb}_{2}$ sample were provided by Jilin Provincial Institute for Drug Control (Changchun, China). All alkali metal salts: $\mathrm{LiCl}, \mathrm{NaCl}, \mathrm{KCl}, \mathrm{RbCl}$, and $\mathrm{CsCl}$ as well as solvents $\mathrm{CHCl}_{3}$ and $\mathrm{MeOH}$ were purchased from Fisher Scientific (Fair Lawn, NJ), and used without further purification.

The crude powder of each herb was extracted with methanol, then the extract was fractionated by silica gel column eluting with different ratios of $\mathrm{CHCl}_{3} / \mathrm{MeOH}$. The fractions were diluted with 50:50 $\mathrm{MeOH} / \mathrm{H}_{2} \mathrm{O}$ and analyzed by ESI-MS ${ }^{\mathrm{n}}$. All samples analyzed were dissolved in methanol-water $\left(10^{-6} \mathrm{~mol} / \mathrm{L}\right)$. In experiments on the effects of alkali metal ion, $10^{-6} \mathrm{~mol} / \mathrm{L}$ alkali metal solutions were mixed as 1:1 with saponin solutions, respectively.

\section{Mass Spectrometry}

All ESI -MS ${ }^{\mathrm{n}}$ experiments were performed on a Finnigan MAT LCQ ion trap mass spectrometer (San Jose, CA) equipped with an electrospray ion source and capable of analyzing ions up to $\mathrm{m} / \mathrm{z}$ 2000. For ESI-MS experiments, the spray voltage was set to $4.5-5.5 \mathrm{kV}$ in positive mode and $-5.0 \mathrm{kV}$ in negative mode. The capillary voltage was fixed at $4.0 \mathrm{~V}$ and the temperature at $200^{\circ} \mathrm{C}$. The ion gauge pressure was $2.4 \times 10^{-5}$ torr. Nitrogen was used as a sheath gas $\left(\sim 5.2 \times 10^{3}\right.$ torr $)$ and the flow rate is 40 arbitrary units. Helium was used as the buffer gas. The ESI interface and mass spectrometer parameters were optimized to obtain maximum sensitivity. For tandem mass spectrometry, the maximum ion injection time was set to $500 \mathrm{~ms}$; the ion isolation width widow was set at 2.0 Th and the collision energies ranged from 36 to $40 \%$. Samples were introduced via a syringe pump at a flow rate of $3 \mu \mathrm{l} / \mathrm{min}$.

\section{Results and Discussion}

Three representative structures of saponins shown in Scheme 1 were taken as examples to study the correlation between CID spectra and structures and illustrate the advantages of ESI-MS ${ }^{\mathrm{n}}$ structural characterization of saponins in this paper.

\section{Determination of Molecular Mass}

Under ESI-MS conditions, saponins have strong molecular species both in positive and negative ion modes. The full-scan mass spectra in positive and negative ion modes of triterpenoidic saponin $\mathrm{Rb}_{2}$ standard sample from Panax Ginseng are shown in Figure 1. Because of the inevitable presence of sodium ions during the process of sample preparation and the strong affinity of sugar to sodium ions in the gas phase [32], all the ESI mass spectra of the saponins are dominated by $[\mathrm{M}+$ $\mathrm{Na}^{+}$ions and exhibit negligible fragmentation. In Figure 1a, the main peak at $m / z 1101$ is assigned to the sodiated adduct $[\mathrm{M}+\mathrm{Na}]^{+}$of ginsenoside $\mathrm{Rb}_{2}$. In negative ion mode (Figure 1b), the deprotonated ion [M $-\mathrm{H}^{-}$at $\mathrm{m} / \mathrm{z} 1077$ is displayed. By comparing this pair of ions, it is easy to confirm the molecular mass of the saponins as $1078 \mathrm{Da}$ for ginsenoside $\mathrm{Rb}_{2}$.

The full-scan positive ion mass spectrum of the saponin mixture extracted from Tribulus terrestris is shown in Figure 2 [29], where at least six peaks were observed at $\mathrm{m} / \mathrm{z}$ 939, 1057, 1071, 1081, 1173, and 1187, illustrating that six saponins from the extract have molecular mass 916, 1034, 1048, 1058, 1150, and 1164 Da.

\section{Structural Characterization}

The fragmentation scheme used in this paper is based on that described by Costello and coworkers [33, 34], where ions retaining the charge at the reducing terminus are termed $\mathrm{Y}$ and $\mathrm{Z}$ (glycosidic cleavages) and $\mathrm{X}$ (cross-ring cleavages) whereas those ions retaining the charge at the non-reducing terminus are termed $\mathrm{B}, \mathrm{C}$ (glycoside cleavages), and A (cross-ring cleavages). Cross-ring cleavage ions are designated by superscript numbers indicating the two bonds cleaved (Scheme 2).

Steroidal saponins. POSITIVE ION MODE. In Figure 2, peak $\mathrm{F}$ at $m / z 1187\left([\mathrm{M}+\mathrm{Na}]^{+}\right)$corresponds to a saponin with a molecular mass $1164 \mathrm{Da}$. According to the literature [29, 30], its structure is assumed to be saponin F (Scheme 1a). The structural analysis of this molecule is taken as an example to illustrate our paradigm.

Figure 3a shows the $\mathrm{MS}^{2}$ spectrum of the $\mathrm{m} / \mathrm{z} 1187$ $\left([\mathrm{M}+\mathrm{Na}]^{+}\right)$ion. $[\mathrm{M}+\mathrm{Na}]^{+}$produces $\mathrm{Y}$ type of fragment ions at $m / z 1055$ and 1041, representing glycosidic cleavage by loss of one pentose residue and one deoxyhexose residue, respectively. The strong intensities of the two ions imply that these sugar residues of pentose and deoxyhexose are located at different ter- 

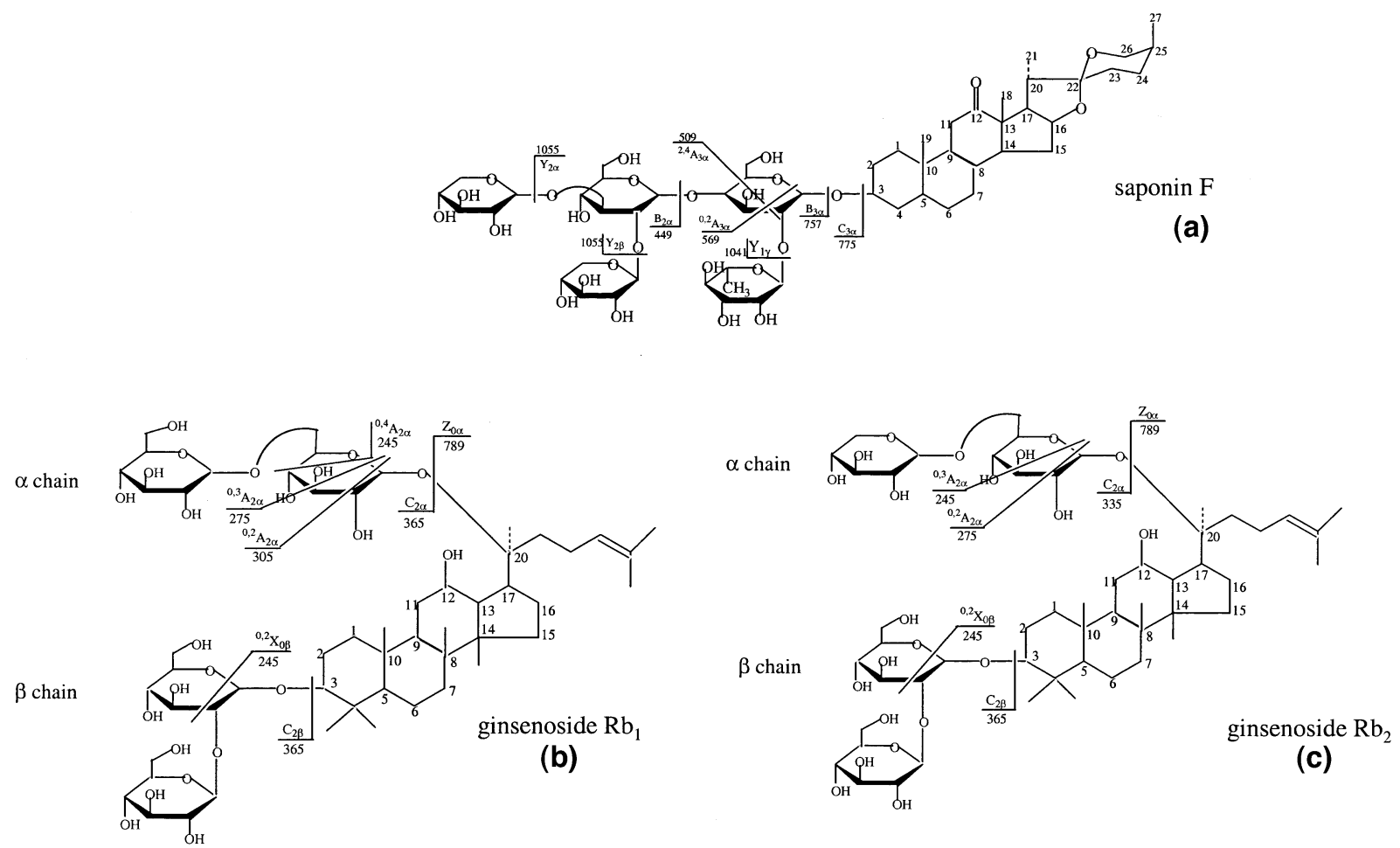

Scheme 1. Structures of saponins in this work and corresponding the fragments of their $[\mathrm{M}+\mathrm{Na}]^{+}$ ions, $(\mathbf{a})$ saponin $\mathrm{F}$ from Tribulus terrestris $(\mathrm{MW}=1164 \mathrm{Da})$; $(\mathbf{b})$ ginsenoside $\mathrm{Rb}_{1}(\mathrm{MW}=1108 \mathrm{Da})$; $(\mathbf{c})$ ginsenoside $\mathrm{Rb}_{2}(\mathrm{MW}=1078 \mathrm{Da})$.

mini of sugar chains. Two weak Y type ions at $\mathrm{m} / \mathrm{z} 923$ and 909 are produced by the simultaneous loss of two pentose residues as well as one pentose and one deoxyhexose residue from $[\mathrm{M}+\mathrm{Na}]^{+}$, indicating that there are at least two pentose residues and one deoxyhexose residue located at the $\alpha, \beta$, and $\gamma$ sugar chain termini, respectively. In principle, ion of $m / z 923$ and 909 should result in two-bond cleavages that yield less abundant product ions from an energy point of view. The mass difference between the $\mathrm{m} / \mathrm{z} 1187$ ion and the $\mathrm{m} / \mathrm{z} 757$ ion is $430 \mathrm{Da}$ corresponding to the mass of the aglycone of neohecogenin [29], which is one kind of aglycone of saponins, while the $\mathbf{B}_{3 \alpha}$ ion at $m / z 757$ represents dehydration ion of a sodiated whole sugar chain, which suggests two more hexose residues besides two pentoses and one deoxyhexose present in a whole sugar chain. $C_{3 \alpha}$ ion at $\mathrm{m} / \mathrm{z} 775$ is formed by glycosidic cleavages as well, but contains a water molecule via the aid of rearrangement of the $\mathrm{H}$ atom. The ions of $\mathrm{m} / \mathrm{z} 625$ and 611 are produced through the loss of an aglycone with one pentose residue $[1187-(430+132)]$ and one deoxyhexose residue $[1187-(430+146)]$, respectively. These low intensity ions involve two bond cleavages and further confirm that these two sugar residues, a pentose and a deoxyhexose residue, are located at different termini of the sugar chain and do not connect with aglycone.

The ion at $\mathrm{m} / \mathrm{z} 449$ corresponds to two pentose residues and one hexose residue $(2 \times 132+162+23)$.
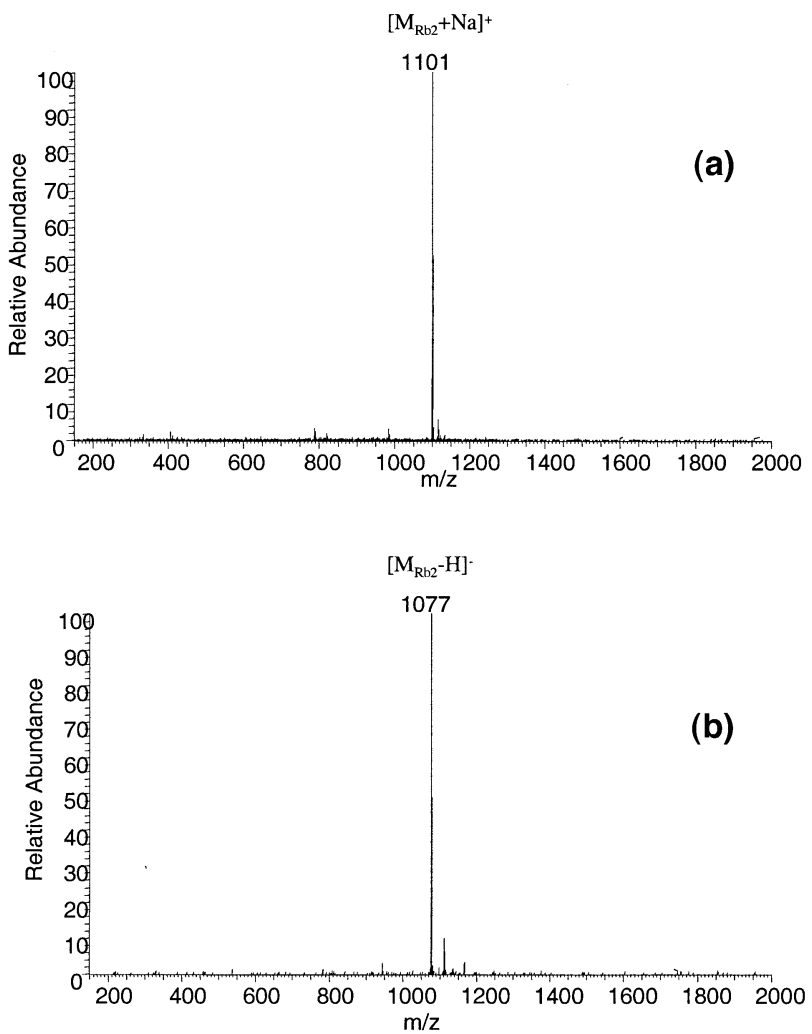

Figure 1. Electrospray mass spectra of ginsenoside $\mathrm{Rb}_{2}$, (a) in positive mode and (b) in negative mode. 




Figure 2. Full-scan positive ion mass spectrum of the steroidal saponin mixture extracted from Tribulus terrestris.

Subsequent CID spectrum of the $\mathrm{m} / \mathrm{z} 449$ ion (Figure $3 \mathrm{~b}$ ) shows only one daughter ion at $\mathrm{m} / \mathrm{z} 317$ produced by the loss of one pentose residue, and no other daughter ions observed suggest that its structure is branching, two pentose residues connected with a hexose residue, respectively.

Figure 3c shows the CID spectrum of the $\mathrm{m} / \mathrm{z} 757$ ion produced from the ion at $m / z$ 1187. It yields the ion at $\mathrm{m} / \mathrm{z} 611$ by the loss of one deoxyhexose residue. The CID spectrum of $m / z 611$ (Figure 3d) indicates losing one hexose residue to produce the $\mathrm{m} / \mathrm{z} 449 \mathrm{ion}$. According to the structure of the $\mathrm{m} / \mathrm{z} 449$ ion mentioned above, the ion at $m / z 611$ should have a branching structure with two pentose residues and one hexose residue at its termini. In addition, the deoxyhexose residue in the $\mathrm{m} / \mathrm{z}$ 757 ion is connected with the terminal hexose residue of the $\mathrm{m} / \mathrm{z} 611$ ion, because there is no fragment ion at $\mathrm{m} / \mathrm{z}$ 595 produced by the loss of one hexose residue in Figure 3c. So the primary sequence and branching of the sugar chain of this saponin were obtained as shown in Scheme 1a. It is apparent that the $\mathrm{Y}$ and B types of fragment ions from sodiated molecular ion are useful for structural elucidation of saponins.

Moreover, some cross-ring ions observed provide the linkage information between sugar residues. Figure $3 e$ shows the CID mass spectrum of the $C_{3 \alpha}$ ion at $\mathrm{m} / \mathrm{z}$ 775. Apart from the fragment ions formed from conventional elimination of water and loss of pentose and deoxyhexose residues, the predominant ion appeared at



Scheme 2. Nomenclature of fragmentation of oligosaccharide by Costello. $\mathrm{m} / \mathrm{z} 569$, which corresponds to the loss of a deoxyhexose residue and a group of $\mathrm{C}_{2} \mathrm{H}_{4} \mathrm{O}_{2}$ from the ion at $\mathrm{m} / z 775$. This was attributed to the 0,2 cross-ring cleavages with the charge retained at the non-reducing terminus, ${ }^{0,2} \mathrm{~A}_{3 \alpha}$, although the generation of ion ${ }^{0,2} \mathrm{~A}_{3 \mathrm{a}}$ requires two-bond cleavage; in the meantime a new bond may be generated to obtain a stable anol form at $\mathrm{C}_{2} \mathrm{H}_{4} \mathrm{O}_{2}$ site, the energy release may make compensation for the two-bond cleavage consumption. Likewise, the ion of $m / z 509$ is designated as ${ }^{2,4} \mathrm{~A}_{3 \alpha}$. These two cross-ring ions illustrate that the deoxyhexose residue linked with the hexose residue at Position 2 and the other part of sugar residue linked with the hexose residue at Position 3 or 4 . Figure $3 \mathrm{f}$ shows that the $C$ type ion at $\mathrm{m} / \mathrm{z} 629$ yields a daughter ion at $m / z 539$, representing a crossring cleavage designated as ${ }^{0,3} \mathrm{~A}_{3 \alpha}$, which further confirms that the other residue is linked with the hexose residue at Position 4 rather than Position 3.

NEGATIVE ION MODE. As we mentioned before, the ESI mass spectra in negative mode involve deprotonated species. Figure 4 shows the $\mathrm{MS}^{\mathrm{n}}$ spectra of a deprotonated molecule $[\mathrm{M}-\mathrm{H}]^{-}$ion at $\mathrm{m} / \mathrm{z} 1163$ of saponin F. $[\mathrm{M}-\mathrm{H}]^{-}$ion gives $\mathrm{Y}$ type of fragment ion at $\mathrm{m} / \mathrm{z} 1031$ by the loss of a pentose residue (Figure 4a). In Figure $4 \mathrm{~b}$, two $\mathrm{Y}$ type ions at $\mathrm{m} / \mathrm{z} 899$ and 737 indicated the loss of one pentose residue as well as one pentose and one hexose residue from $\mathrm{m} / \mathrm{z} 1031$, respectively. In the following tandem mass spectrometry experiment, subsequent $\mathrm{Y}$ type ions were obtained and finally the $\mathrm{m} / \mathrm{z} 591$ ion was produced, which is the aglycone with one hexose residue. There is no cross-ring ion detected at all, which makes a tremendous difference between the negative and positive mode spectra. During the ESI process, for the formation of positive ions, a saponin molecule combines with an alkali metal ion to generate a new bond, which is an exothermic reaction. The energy released is deposited into the internal degree of freedom and may excite more bond cleavages under CID conditions. So, many fragments are obtained in the CID spectra in positive ion mode. In contrast, the formation of $[\mathrm{M}-\mathrm{H}]^{-}$ions involves a proton loss from a neutral molecule, which needs extra energy prior to fragmentation and is endothermic [35]. Therefore [M $\mathrm{H}]^{-}$ions have less internal energy than their positive counterparts and undergo fewer steps of CID. This is the reason why ESI-MS ${ }^{\mathrm{n}}$ spectra of $[\mathrm{M}-\mathrm{H}]^{-}$ions of saponins provide structural information on the sequence of sugar chains with lower sensitivity than that in positive ion mode.

Triterpenoidic saponins (dammarane type). Here we studied two species of triterpenoidic saponins, ginsenoside $\mathrm{Rb}_{1}$ (Scheme 1b) and $\mathrm{Rb}_{2}$ (Scheme 1c) [3]. The former molecule has two similar disaccharide chains in composition, connected at $C_{3}$ and $C_{20}$, respectively, but the two chains have different linkages.

Figure 5 shows the $\mathrm{MS}^{\mathrm{n}}$ spectra of $[\mathrm{M}+\mathrm{Na}]^{+}$ion at $m / z 1131$ of ginsenoside $\mathrm{Rb}_{1}$. The $\left[\mathrm{M}+\mathrm{Na}^{+}\right.$ion 

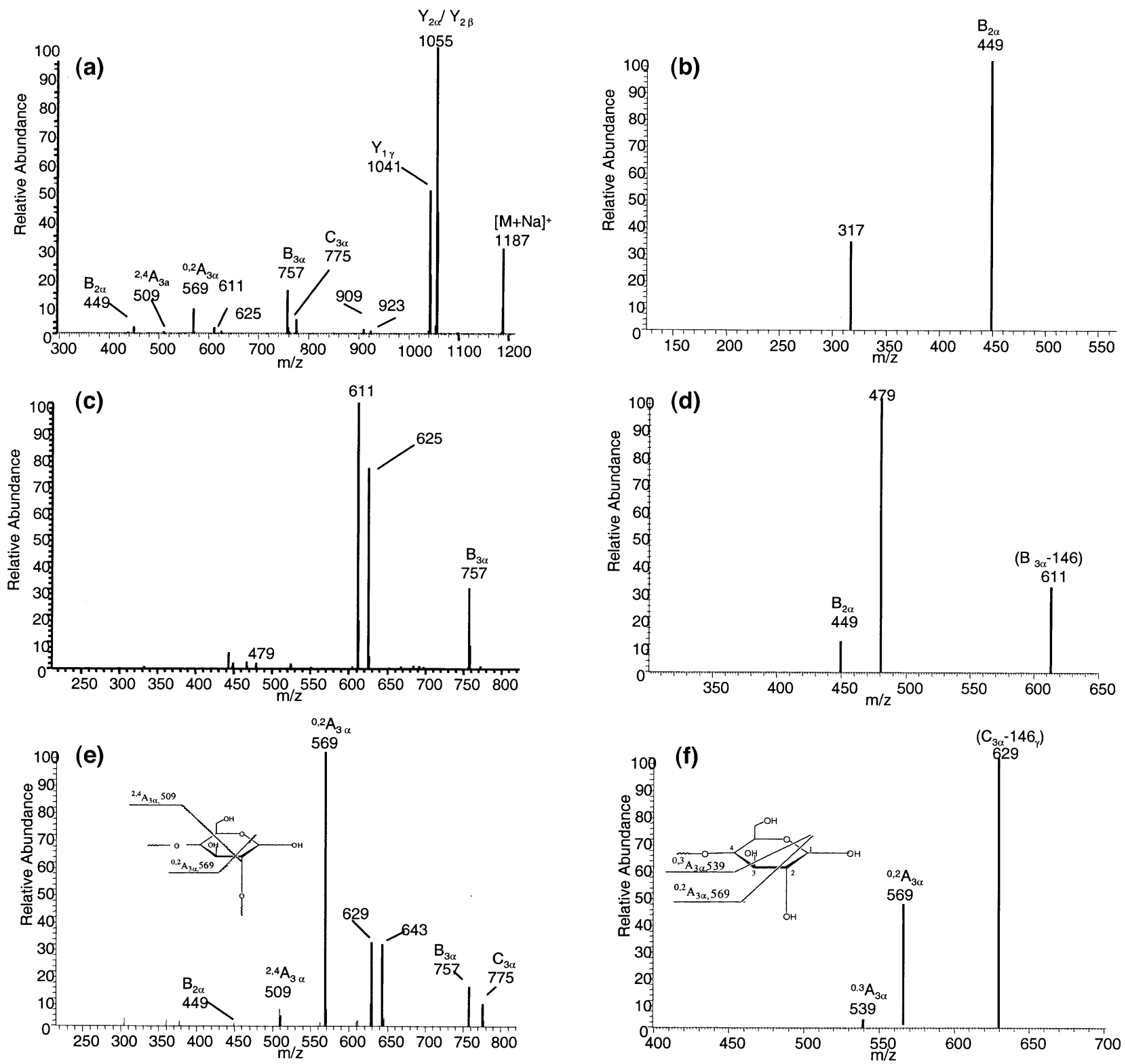

Figure 3. $\mathrm{MS}^{\mathrm{n}}$ spectra on $[\mathrm{M}+\mathrm{Na}]^{+}$ion at $m / z 1187$ of saponin A from Tribulus terrestris, (a) $\mathrm{MS}^{2}$ spectrum of $m / z 1187$ ion $\left([\mathrm{M}+\mathrm{Na}]^{+}\right)$; (b) $\mathrm{MS}^{3}$ spectrum of $m / z 449$ ion from the $m / z 1187$ ion $([\mathrm{M}+$ $\left.\mathrm{Na}^{+}\right)(1187>449>)$; (c) $\mathrm{MS}^{3}$ spectrum of $m / z 757$ ion from $m / z 1187$ ion $\left([\mathrm{M}+\mathrm{Na}]^{+}\right)(1187>757>)$; (d) $\mathrm{MS}^{4}$ spectrum of $\mathrm{m} / \mathrm{z} 611$ ion from the $\mathrm{m} / \mathrm{z} 1187$ ion $\left([\mathrm{M}+\mathrm{Na}]^{+}\right)(1187>757>611>)$; (e) $\mathrm{MS}^{3}$ spectrum of $m / z 757$ ion from the $m / z 1187$ ion $\left([\mathrm{M}+\mathrm{Na}]^{+}\right)(1187>775>)$; (f) $\mathrm{MS}^{4}$ spectrum of $\mathrm{m} / \mathrm{z}$ 629 ion from $m / z 1187$ ion $\left([\mathrm{M}+\mathrm{Na}]^{+}\right)(1187>775>629>)$.

produces two fragments: the $Z_{0 \alpha}$ at $m / z 789$ ion by the loss of two hexose residues and the sodiated dihexoses $\mathrm{C}_{2 \alpha}$ ion at $m / z 365$ because of the higher reactivity of $\mathrm{C}_{20}$ than that of $\mathrm{C}_{3}$ (Figure 5a). In Figure $5 \mathrm{~b}$, the $\mathrm{Z}_{0 \alpha}(\mathrm{m} / \mathrm{z}$ $789)$ ion yields a daughter ion at $m / z 365$ ion $\left(C_{2 \beta}\right)$. The mass difference $424 \mathrm{Da}$ between the $\mathrm{m} / \mathrm{z} 789$ and 365 ions is in agreement with the mass of the aglycone (panaxdiol, molecule mass 460) with the loss of two water molecules. The different CID spectra of $\mathrm{C}_{2 \alpha}$ and $\mathrm{C}_{2 \beta}$ ions at $m / z 365$ (Figure $5 \mathrm{c}-\mathrm{d}$ ) show their different structures. In Figure $5 c(1131>789>365>), C_{2 \beta}$ ion mainly produces ${ }^{0,2} X_{0 \beta}(m / z 245)$ ion by the cross-ring cleavages at the 0,2 two bonds, which means that the $\beta$ chain consists of two hexoses connected to each other at the 1,2 position. However, in Figure $5 d(1131>365>)$, the $\mathrm{C}_{2 \alpha}$ ion at $m / z 365$ produced directly from [M+ $\mathrm{Na}]^{+}$ion showed different CID behavior, yielding a series of cross-ring ions attributed to ${ }^{0,2} \mathrm{~A}_{2 \alpha}$ at $m / z$ 305, ${ }^{0,3} \mathrm{~A}_{2 \alpha}$ at $m / z 275,{ }^{0,4} \mathrm{~A}_{2 \alpha}$ at $m / z 245$. Those ions provide important information on the linkage, a hexose linked with the other at Position 6 in the $\alpha$-sugar chain at $\mathrm{C}_{20}$. So it is obvious that the cleavage of the oligosaccharide 


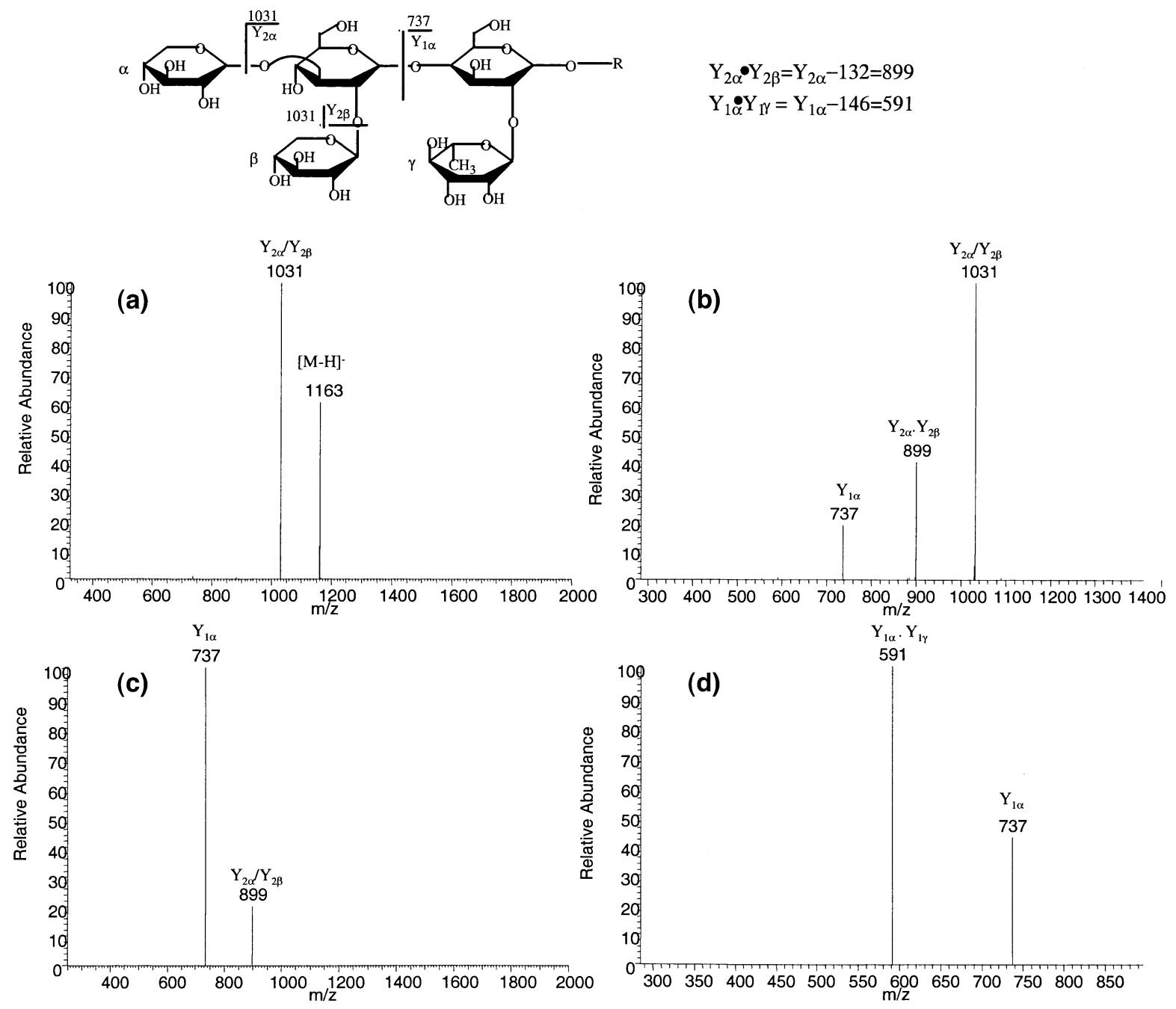

Figure 4. Negative ion ESI MS ${ }^{n}$ mass spectra on $[\mathrm{M}-\mathrm{H}]^{-}$ion at $m / z 1163$ of Saponin A from Tribulus terrestris, (a) MS ${ }^{2}$ spectrum of the $m / z 1163$ ion $\left(\left[\mathrm{M}-\mathrm{H}^{-}\right)\right.$; (b) $\mathrm{MS}^{3}$ spectrum of $m / z 1031$ ion from the $\mathrm{m} / z 1163$ ion $\left([\mathrm{M}-\mathrm{H}]^{-}\right)(1163>1031>)$; (c) $\mathrm{MS}^{4}$ spectrum of $\mathrm{m} / \mathrm{z} 899$ ion from $\mathrm{m} / \mathrm{z} 1163$ ion ([M $\left.\mathrm{H}^{-}\right)(1163>1031>899>)$; (d) MS ${ }^{5}$ spectrum of $m / z 737$ ion from $m / z 1163$ ion $\left([\mathrm{M}-\mathrm{H}]^{-}\right)(1163>$ $1031>899>737>$ ).

residue first happens at $\mathrm{C}-20$ of aglycone. This is in agreement with the results of the acidic hydrolysis of dammarane saponins [36]. In the solution of the saponin, hydrolysis gave faster cleavage at C-20 than at the $\mathrm{C}-3$ hydroxyl group and resulted in sugar loss from the aglycone moiety. Ginsenoside $\mathrm{Rb}_{2}$ with two different sugar chains was investigated with similar results (data not shown), and the same conclusion was obtained.

Effects on the fragmentation of saponins by adding alkali metal salts. After each of different alkali metal salts was added to the saponin solution, under positive ion mode ESI experimental conditions, the related adduct cations were produced in the gas phase. Here we take two ginsenosides $R b_{1}$ and $R b_{2}$ as examples to study the alkali metal effects. For adduct ions of $[\mathrm{M}+\mathrm{Rb}]^{+}$and $[\mathrm{M}+\mathrm{Cs}]^{+}$, no fragmentation was observed in CID experiments. But $[\mathrm{M}+\mathrm{Li}]^{+},[\mathrm{M}+\mathrm{Na}]^{+}$and $[\mathrm{M}+\mathrm{K}]^{+}$ adduct ions showed different behavior in multi-stage tandem mass spectrometry. Tables 1, 2, and 3 list $\mathrm{MS}^{\mathrm{n}}$ data of these metal adducts. With increasing atomic number of metals, the tendency of fragmentation from glycosidic cleavage and cross-ring cleavages decrease. Different CID behavior depends on the internal energy of the adduct ions. At this time we have not obtained the affinity values of alkali ions for saponins, however, as we mentioned all ions that appeared in the positive ion mode ESI of saponins were linked sugar residues, so here we approximated a few affinity values of alkali ions for glucose instead of those for saponins. The $\mathrm{Na}^{+}$ affinity for glucose is around $160 \mathrm{~kJ} / \mathrm{mol}$ and $\mathrm{Li}^{+}$ affinity for glucose is $250 \mathrm{~kJ} / \mathrm{mol}[32,35]$, so in the course of forming metal adduct ions, more energy deposits into the internal degree of freedom of the product ions $\left[\mathrm{M}+\mathrm{Li}^{+}\right.$than that into $[\mathrm{M}+\mathrm{Na}]^{+}$. Therefore $[\mathrm{M}+\mathrm{Li}]^{+}$ions have more internal energy 

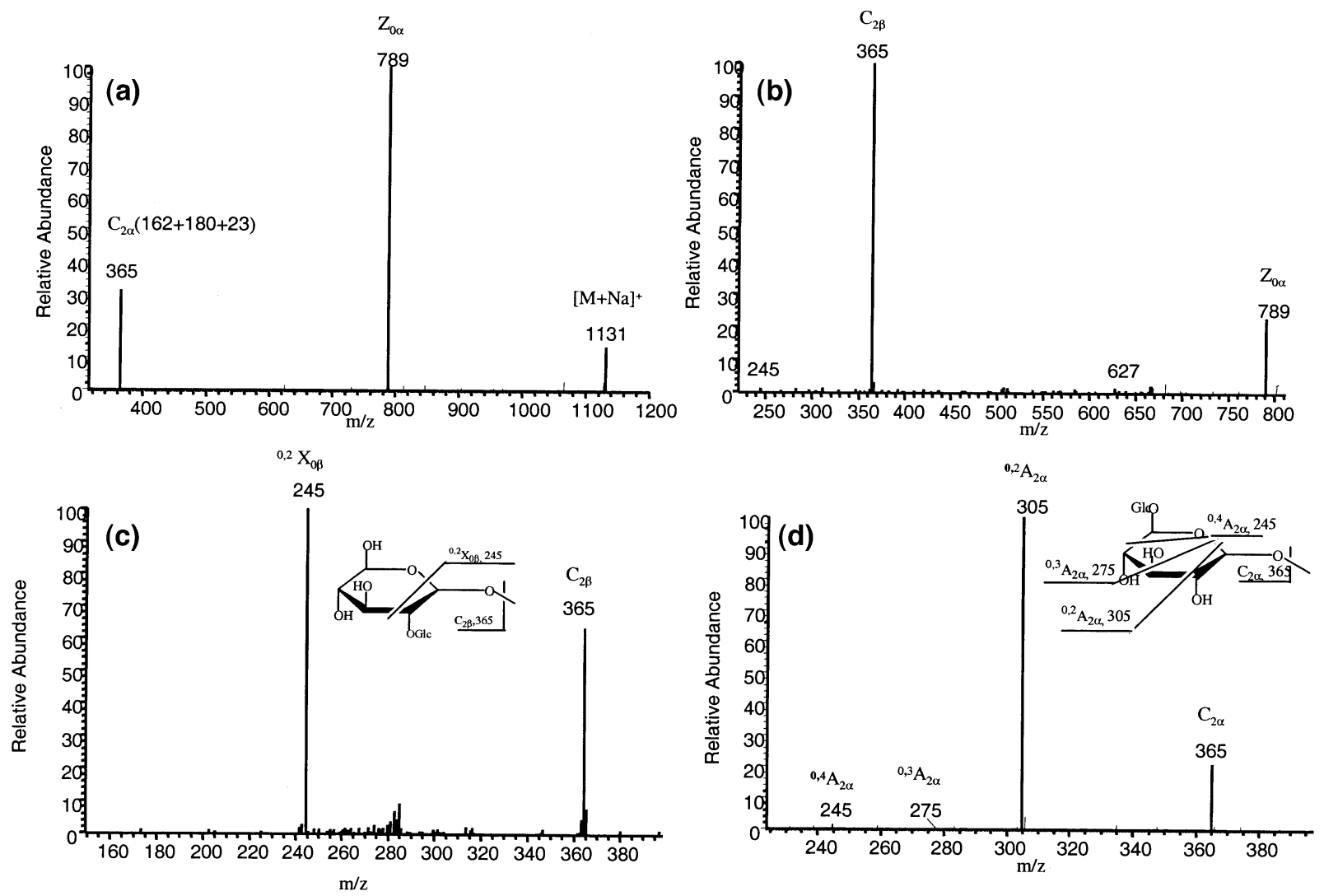

Figure 5. Positive ion ESI MS ${ }^{n}$ mass spectra of ginsenoside $\mathrm{Rb}_{1}$, a) $\mathrm{MS}^{2}$ spectrum of $\mathrm{m} / z 1131$ ion ([M $\left.+\mathrm{Na}^{+}\right)$; (b) $\mathrm{MS}^{3}$ spectrum of $m / z 789$ ion from $m / z 1131$ ion $\left([\mathrm{M}+\mathrm{Na}]^{+}\right)(1131>789>)$; (c) $\mathrm{MS}^{4}$ spectrum of $\mathrm{m} / \mathrm{z} 365$ ion from $\mathrm{m} / \mathrm{z} 1131$ ion $\left(1131>789>365>\right.$ ); (d) $\mathrm{MS}^{3}$ spectrum of $\mathrm{m} / \mathrm{z} 365$ ion from the $m / z 1131$ ion $(1131>365>)$.

than $[\mathrm{M}+\mathrm{Na}]^{+}$ions. Many more fragment ions, including cross-ring ions which needs more energy, have been observed for $[\mathrm{M}+\mathrm{Li}]^{+}$than for $[\mathrm{M}+\mathrm{Na}]^{+}$
(Table1), which can be complementary for the shortage of structural information provided by $[\mathrm{M}+\mathrm{Na}]^{+}$adducts. Similarly, there are more fragment ions from $[\mathrm{M}+\mathrm{Na}]^{+}$

Table 1. Fragmentation pathways of ESI-MS ${ }^{\mathrm{n}}$ on $\left[\mathrm{M}_{\mathrm{Rb} 1}+\mathrm{Li}\right]^{+}$and $\left[\mathrm{M}_{\mathrm{Rb} 2}+\mathrm{Li}\right]^{+}$

\begin{tabular}{|c|c|c|c|c|}
\hline Precursor & $\mathrm{MS}^{2}$ & $\mathrm{MS}^{3}$ & $\mathrm{MS}^{4}$ & $\mathrm{MS}^{5}$ \\
\hline \multirow[t]{2}{*}{$1115_{\left[M_{R b 1}+L_{i}\right]^{+}}$} & $\begin{array}{l}773_{\left(z_{1 \alpha}\right)} \\
611_{\left(\gamma_{2 \beta}\right)}\end{array}$ & $\begin{array}{c}349_{\left(\mathrm{C}_{1 \beta}\right)} \\
593_{\left(-\mathrm{H}_{2}\right)} 449_{\left(\mathrm{Y}_{1 \beta}\right)} \\
521_{\left(0,2 \mathrm{~A}_{1 \beta}\right)} \\
491_{\left(0, \mathrm{~A}_{1 \beta}\right)} \\
431_{\left(\mathrm{Z}_{1 \beta}\right)}\end{array}$ & $\left.229_{(0,2} x_{1 \beta}\right)$ & $187_{\left(\mathrm{C}_{2 \beta}\right)} 169_{\left(\mathrm{B}_{2 \beta}\right)}$ \\
\hline & $349_{\left(c_{1 \alpha}\right)}$ & $\begin{array}{c}\left.289_{(0,2} \mathrm{A}_{1 \alpha}\right) \\
\left.229_{(0,4}^{0,4} \mathrm{~A}_{1 \alpha}\right) \\
187_{\left(\mathrm{Y}_{2 \beta}\right)} \\
169_{\left(\mathrm{Z}_{2 \beta}\right)}\end{array}$ & $\begin{array}{l}259_{(0,3}^{\left.0, A_{1 \alpha}\right)} \\
\quad 187_{\left(Y_{2 \beta}\right)} 169_{\left(Z_{2 \beta}\right)}\end{array}$ & $229_{\left({ }^{0,4} \mathrm{~A}_{1 \alpha}\right)} 187_{\left(\mathrm{Y}_{2 \beta}\right)}$ \\
\hline \multirow[t]{3}{*}{$1085_{\left[\mathrm{RBb}_{\mathrm{Rb}}+\mathrm{Li}\right]^{+}}$} & $773_{\left(z_{1 \alpha}\right)}$ & $\begin{array}{l}349_{\left(C_{1 \beta}\right)} \\
611_{\left(Y_{2 \beta}\right)}\end{array}$ & $\begin{array}{l}\left.229_{\left(0,2 \mathrm{X}_{1 \beta}\right)}\right) \\
593_{\left(-\mathrm{H}_{2} \mathrm{O}\right)} 449_{\left(\mathrm{Y}_{1 \beta}\right)} \\
521_{\left(0,2 \mathrm{~A}_{1 \beta}\right)} \\
\left.491_{1}, 3_{1 \beta} \mathrm{A}_{1 \beta}\right) \\
431_{\left(\mathrm{Z}_{1 \beta}\right)}\end{array}$ & $187_{\left(\mathrm{C}_{2 \beta}\right)} 169_{\left(\mathrm{B}_{2 \beta}\right)}$ \\
\hline & $333_{\left(C_{1 \alpha}\right)}$ & $\left.273_{0,2} \mathrm{~A}_{1 \alpha}\right)$ & $243_{\left(0,3 A_{1 \alpha}\right)}$ & $\begin{array}{c}213_{(0,4}^{0,4} A_{\left.A_{1}\right)} 187_{\left(Y_{2 \beta}\right)} \\
169_{\left(Z_{2 \beta}\right)}\end{array}$ \\
\hline & & $\begin{array}{r}243_{\left({ }^{0,3} \mathrm{~A}_{1 \alpha}\right)} \\
\left.213_{(0,4} \mathrm{A}_{1 \alpha}\right) \\
187_{\left(\mathrm{Y}_{2 \beta}\right)} \\
169_{\left(\mathrm{Z}_{2 \beta}\right)}\end{array}$ & $\begin{array}{r}213_{\left(0,4 A_{1 \alpha}\right)} \\
187_{\left(Y_{2 \beta}\right)}\end{array}$ & $\begin{array}{l}187_{\left(Y_{2 \beta}\right)} 169_{\left(Z_{2 \beta}\right)} \\
169_{\left(Z_{2 \beta}\right)}\end{array}$ \\
\hline
\end{tabular}


Table 2. Fragmentation pathways of ESI-MS ${ }^{\mathrm{n}}$ on $\left[\mathrm{M}_{\mathrm{Rb} 1}+\right.$ $\mathrm{Na}]^{+}$and $\left[\mathrm{M}_{\mathrm{Rb} 2}+\mathrm{Na}\right]^{+}$

\begin{tabular}{|c|c|c|c|}
\hline Precursor & $\mathrm{MS}^{2}$ & $\mathrm{MS}^{3}$ & $\mathrm{MS}^{4}$ \\
\hline $1131_{\left[\mathrm{M}_{\mathrm{Rb} 1}+\mathrm{Na}\right]^{+}}$ & $\begin{array}{l}789_{\left(z_{1 \alpha}\right)} \\
365_{\left(C_{1 \alpha}\right)}\end{array}$ & $\begin{array}{r}365_{\left(\mathrm{C}_{1 \beta}\right)} \\
627_{\left(\mathrm{Y}_{2 \beta}\right)} \\
\left.305_{(0,2} \mathrm{A}_{1 \alpha}\right) \\
\left.275_{(0,3} \mathrm{A}_{1 \alpha}\right) \\
245_{\left({ }^{0,4} \mathrm{~A}_{1 \alpha}\right)}\end{array}$ & $245\left(0,2 x_{1 \beta}\right)$ \\
\hline $1101_{\left[\mathrm{M}_{\mathrm{Rb} 2}+\mathrm{Na}\right]^{+}}$ & $\begin{array}{l}789_{\left(z_{1 \alpha}\right)} \\
335_{\left(c_{1 \alpha}\right)}\end{array}$ & $\begin{array}{r}365_{\left(\mathrm{C}_{1 \beta}\right)} \\
627_{\left(\mathrm{Y}_{2 \beta}\right)} \\
\left.275^{0,2} \mathrm{~A}_{1 \alpha}\right) \\
\left.245^{0,3} \mathrm{~A}_{1 \alpha}\right) \\
\left.215^{(0,4} \mathrm{A}_{1 \alpha}\right)\end{array}$ & $245\left({ }^{0,2} x_{1 \beta}\right)$ \\
\hline
\end{tabular}

than $[\mathrm{M}+\mathrm{K}]^{+}$(Table 3). In general, $[\mathrm{M}+\mathrm{Na}]^{+}$gives a fair degree of fragmentation via several stage CID, which provides both sugar sequence and linkage information.

It was found that in the positive ion mode of ESI mass spectra for saponins, all the ions contain, at least, one sugar unit; the observed peaks are all assigned to $[\mathrm{M}+\mathrm{Na}]^{+}$ions without extra sodium salts added; no protonated molecules were observed because proton affinity for saponins probably is too high $(778 \mathrm{~kJ} / \mathrm{mol}$ for glucose [35]) that the $[\mathrm{M}+\mathrm{H}]^{+}$may exist only for a very short life time.

\section{Conclusions}

It has been demonstrated that ESI-MS ${ }^{n}$ is a fast, effective and practical tool to characterize the structures of underivatized saponins in crude extracts from medicinal herbs, avoiding the handling of saponins from derivation to complete separation. The molecular ions of saponins show the characteristic mass spectrometry behavior. In positive mode, the predominant $[\mathrm{M}+$ $\mathrm{Na}]^{+}$of saponins yields $\mathrm{Y}, \mathrm{Z}, \mathrm{B}$, and $\mathrm{C}$ types of fragment ions providing the information of the primary sequence and branching in terms of classes of monosaccharides in oligosaccahride chain in saponins and the cross-ring A and $\mathrm{X}$ types of ions providing the information of linkages between sugar residues. In negative ion mode, deprotonated ions $[\mathrm{M}-\mathrm{H}]^{-}$only yield a few $\mathrm{Y}$ or $\mathrm{B}$ and no cross-ring ions because of the internal energy of precursor $[\mathrm{M}-\mathrm{H}]^{-}$ions.

Upon adding alkali metal ions to saponins, the adduct ions were generated in gas phase. Different metal ions affect the degree of fragmentation tremen-

Table 3. Fragmentation pathways on $\left[\mathrm{M}_{\mathrm{Rb} 1}+\mathrm{K}\right]^{+}$and $\left[\mathrm{M}_{\mathrm{Rb} 2}\right.$ $+\mathrm{K}^{+}$

\begin{tabular}{lc}
\hline Parent ions & $\mathrm{MS}^{2}$ \\
\hline \hline $1147_{\left[\mathrm{M}_{\mathrm{Rb} 1}+\mathrm{K}\right]^{+}}$ & $985_{\left(\mathrm{Z}_{2 \alpha}\right)}$ \\
& $805_{\left(\mathrm{Z}_{1 \alpha}\right)}$ \\
$1117_{\left[\mathrm{M}_{\mathrm{Rb} 2}+\mathrm{K}\right]^{+}}$ & $381_{\left(\mathrm{C}_{1 \alpha}\right)}$ \\
& $985_{\left(\mathrm{Z}_{2 \alpha}\right)}$ \\
& $805_{\left(\mathrm{Z}_{1 \alpha}\right)}$ \\
& $351_{\left(\mathrm{C}_{1 \alpha}\right)}$ \\
\hline
\end{tabular}

dously. With increasing atom mass of alkali metal, the adduct ions produce fewer daughter ions and have fewer generations of descendents starting with $\mathrm{Li}$, until $[\mathrm{M}+\mathrm{Rb}]^{+}$and $[\mathrm{M}+\mathrm{Cs}]^{+}$have none at all. In general, $[\mathrm{M}+\mathrm{Na}]^{+}$ions give a fair degree of fragmentation via several stages of CID providing both sugar sequence and linkage information, whereas $\left[\mathrm{M}+\mathrm{Li}^{+}\right.$ions give a much higher degree of fragmentations, which leads to complexity of spectra, but in some cases may provide more detailed information to compensate for the shortage from other sources.

\section{Acknowledgments}

This work was supported by the National Natural Science Foundation of China (grants no. 39930210 and no. 20173057). The authors thank Mr. Victor J. Boyko of the National Research Council of Canada for his help in reading this manuscript.

\section{References}

1. Hostettmann, K.; Marston, A. Saponins; Cambridge University Press: New York, NY, 1995, pp. 232-306.

2. Benishin, C. G.; Lee, R.; Wang, L. C. H.; Liu, H. J. Effects of Ginsenoside $\mathrm{R}_{\mathrm{b} 1}$ on Central Cholinergic Metabolism. Pharmacology 1991, 42, 223-229.

3. Attele, A. S.; Wu, J. A.; Yuan, C. S. Ginseng Pharmacology: Multiple Constituents and Multiple Actions. Biochem. Pharmacol. 1999, 58, 1685-1693.

4. Yoshiki, Y.; Kudou, S.; Okubo, K. Relationship Between Chemical Structures and Biological Activities of Triterpenoid Saponins from Soybean. Biosci. Biotechnol. Biochem. 1998, 62, 2291-2300.

5. Akiyama, T.; Tanaka, O.; Shibata, S. Chemical Studies on the Oriental Plant Drugs, XXXII. Saponins of the Roots of Platycodon Grandiflorum A. De Candolle(3). The Structure of a Prosapogenin, 3-O-B-Glucosylplatycodigenin. Chem. Pharm. Bull. 1972, 20(9), 1957-1961.

6. Van Atta, G. R.; Guggolz, J.; Thompson, C. R. Plant Analysis, Determination of Saponins in Alfalfa. J. Agric. Food Chem. 1961, 9, 77-79.

7. Komori, T.; Tanaka, O.; Nagai, Y. Studies on Saponins from Medicinal Ginseng Root-Mass Spectra of Ginsenoside- $R_{\mathrm{g} 1}$ Decaacetate and Related Compounds. Org. Mass Spectrom. 1974, 9(8), 744-752.

8. Yahara, S.; Kasai, R.; Tanaka, O. New Dammarane Type Saponins of Leaves of Panax Japonicus C.A. Meyer(I) Chikusetususaponins $-\mathrm{L}_{5}-\mathrm{L}_{9 \mathrm{a}}$ and $\mathrm{L}_{10}$. Chem. Pharm. Bull. 1977, 25(8), 2041-2047.

9. Price, K. R.; Curl, C. L.; Fenwick, G. R. Saponin Composition of 13 Varieties of Legume Seed Using Gast Atom Bombardment Mass-Spectrometry. J. Sci. Food Agric. 1988, 42, 183-193.

10. Hostettmann, K.; Doumas, J.; Hardy, M. Desorption-Chemical Ionization Mass Spectrometry of Naturally-Occurring Glycosides. Helv. Chim. Acta 1981, 64, 297-303.

11. Schulten, H. R.; Komori, T.; Nohara, T.; Higuchi, R.; Kawasaki, T. Field Desorption Mass Spectrometry of Natural Products, II. Physiologically Active Pennogenin and Hederagenin-Glycosides. Tetrahedron 1978, 34, 1003-1010.

12. Adlercreutz, H.; Soltmann, B.; Tikkanen, M. J. Field Desorption Mass Spectrometry in the Analysis of a Steroid Conjugate, Estriol-16-Glucuronide. J. Steroid Biochem. 1974, 5, 163-166.

13. Schulten, H. R.; Komori, T.; Kawasaki, T. Field Desorption Mass Spectrometry of Natural Products, I. Steroid- and Triterpene Saponins. Tetrahedron 1977, 33, 2595-2602. 
14. Kawasaki, T.; Komori, T.; Schulten, H. R. Field Desorption and Fast Atom Bombardment Mass Spectrometry of Biologically Active Natural Oligoglycosides. Mass Spectrom. Rev. 1985, 4, 255-293.

15. Borel, C.; Hostettmann, K. Molluscicidal Saponins from Swartzia madagascariensis Desvaux. Helv. Chim. Acta 1987, 70, 570-576.

16. Lee, M. R.; Chen, C. M.; Hwang, B. H.; Hsu, L. M. Analysis of Saponins from Black Bean by Electrospray Ionization and Fast Atom Bombardment Tandem Mass Spectrometry. J. Mass Spectrom. 1999, 34(8), 804-812.

17. Chen, Y. Z.; Chen, N. Y.; Li, H. Q.; Zhao, F. Z.; Chen, N. Fast Atom Bombardment and Collision Activation Mass Spectrometry in the Structure Analysis of Steroidal Oligoglycosides. Biomed. Environ. Mass Spectrom. 1987, 14, 9-15.

18. Zhao, F. Z.; Li, H. Q.; Zhai, J. J.; Chen, N. Y.; Chen, Y. Z. X. The Study of Alkali Metal Adduct Ions Technique of Glycosides in Fast Atom Bombardment Mass Spectrometry. Acta Chim. Sinica 1991, 49(1487.

19. Mclafferty, F. W.; Fridriksson, E. K.; Horn, D. M.; Lewis, M. A.; Zubarey, R. A. Techview: Biochemistry. Biomolecule Mass Spectrometry. Science 1999, 284, 1289-1290.

20. Wilm, M.; Shevchenko, A.; Houthaeve, T. Femtomole Sequencing of Proteins from Polyacrylamide Gels by NanoElectrospray Mass Spectrometry. Nature 1996, 379(6564), $466-$ 469.

21. Shen, X.; Perreault, H. Electrospray Ionization Mass Spectrometry of 1-Phenyl-3-Methyl-5-Pyrazolone Derivatives of Neutral and N-acetylated Oligosaccharides. J. Mass Spectrom. 1999, 34, 502-510.

22. Chai, W.; Piskarev, V.; Lawson, A. M. Negative-Ion Electrospray Mass Spectrometry of Neutral Underivatized Oligosaccharides. Anal. Chem. 2001, 73(3), 651-657.

23. van Stetten, D. C.; ten Hove, G. J.; Wiertz, E. J. H. J.; Kamerling, J. P.; van de Werken, G. Multiple-Stage Tandem Mass Spectrometry for Structural Characterization of Saponins. Anal. Chem. 1998, 70, 4401-4409.

24. Schopke, T.; Hiller, K.; Wray, V.; Nimtz, M. Application of MS-MS for the Rapid, Comparative Analysis of Saponin Mixtures as Exemplified by the Deacylated and Partially Deacylated Triterpenoid Saponins of Bellis annua. Planta Med. 1996, 62, 336-340.

25. Lommen, A.; Godejohann, M.; Venema, D. P.; Hollman, P. C. H.; Spraul, M. Application of Directly Coupled HPLCNMR-MS to the Identification and Confirmation of Quercetin
Glycosides and Phloretin Glycosides in Apple Peel. Anal. Chem. 2000, 72, 1793-1797.

26. Cai, Z. W.; Lee, F. S. C.; Wang, X. R.; Yu, W. J. A Capsule Review of Recent Studies on the Application of Mass Spectrometry in the Analysis of Chinese Medicinal Herbs. J. Mass Spectrom. 2002, 37, 1013-1024.

27. Wang, X. M.; Sakuma, T.; Cheng, S. W.; Kowok, I. M. Y.; Lau, F. W.; Xu, H. X. Determination of Ginsenosides in Plant Extracts from Panax ginseng and Panax quinquefolius L. by LC/MS/MS. Anal. Chem. 1999, 71, 1579-1584.

28. Strife, R. J.; Ketcha, M. M.; Schwartz, J. Multi-Stage Mass Spectrometry for the Isolation and Structure Elucidation of Components of a Crude Extract. J. Mass Spectrum. 1997, 32, 1226-1234.

29. Fang, S. P.; Hao, C. Y.; Sun, W. X.; Liu, Z. Q.; Liu, S. Y. Rapid Analysis of Steroidal Saponin Mixture Using Electrospray Ionization Mass Spectrometry Combined with Sequential Tandem Mass Spectrometry. Rapid Commun. Mass Spectrom. 1998, 12, 589-594.

30. Fang, S. P.; Hao, C. Y.; Liu, Z. Q.; Song, F. R.; Liu, S. Y. Application of Electrospray Ionization Mass Spectrometry Combined with Sequential Tandem Mass Spectrometry Techniques for the Profiling of Steroidal Saponin Mixture Extracted from Tribulus terrestris. Planta Med. 1999, 65, 68-73.

31. Cui, M.; Song, F. R.; Zhou, Y.; Liu, Z. Q.; Liu, S. Y. Rapid Identification of Saponins in Plant Extracts by Electrospray Ionization Multi-stage Tandem Mass Spectrometry and Liquid Chromatography/tandem Mass Spectrometry. Rapid Commun. Mass Spectrom. 2000, 14, 1280-1286.

32. Li, P. Ph.D. Thesis, Hong Kong Polytechnic University, 1999; Mass Spectrometric Studies on Monosacharides and Oligosaccharides.

33. Domon, B.; Costello, C. E. A Systematic Nomenclature for Carbohydrate Fragmentations in FAB-MS/MS Spectra of Glycoconjugates. Glycoconj J. 1988, 5, 397-409.

34. Perreault, H.; Costello, C. E. Liquid Secondary Ionization Tandem and Matrix-Assisted Laser Desorption/Ionization Time-of-Flight Mass Spectrometric Characterization of Glycosphingolipid Derivatives. Org. Mass Spectrom. 1994, 29, 720 -735 .

35. Hunter, E. P.; Lias, S. G. J. Phys. Chem. Ref. Data 1998, 27(3), 413.

36. Zhou, K.; Zhu, S.; Tohda, C.; Cai, S. Q.; Komatsu, K. Dammarane-Type Triterpene Saponins from Panax japonicus. J. Nat. Prod. 2002, 65, 346-351. 